\title{
EFFECT OF PRICE-SENSITIVE DEMAND AND DEFAULT RISK ON OPTIMAL CREDIT PERIOD AND CYCLE TIME FOR A DETERIORATING INVENTORY MODEL
}

\author{
Asim Paul ${ }^{1}$, Magfura Pervin ${ }^{2}$, Sankar Kumar Roy ${ }^{1, *}$, \\ Gerhard-Wilhelm Weber ${ }^{3,4}$ And Abolfazl Mirzazadeh ${ }^{5}$
}

\begin{abstract}
In this paper, we formulate and solve an economic order quantity model with default risk. Our main purpose is to investigate retailer's optimal replenishment time and credit period for deteriorating items under selling price-dependent demand while maximizing profit per unit time. Here, shortages are allowed and items are partially backlogged for interested customers. We show that optimal replenishment time and credit period not only exist but they are also unique. We solve the proposed problem analytically. An algorithm is presented to derive the optimal solution of the model. The mathematical model is evaluated by numerical examples. We use Mathematica to obtain a global maximum solution to the optimal cycle time and the optimal credit period for the proposed model. A sensitivity analysis with respect to major parameters is performed in order to examine the stability of our model. At the end of the paper, conclusions are drawn and an outlook of possible future directions is depicted.
\end{abstract}

Mathematics Subject Classification. 90B05, 90C31.

Received July 31, 2020. Accepted September 23, 2020.

\section{INTRODUCTION}

Inventory control is a main pillar in business system. Many researchers have been attracted by the topic of inventory control, because it depends on companies which are the backbone of developed and emerging countries. Inventory is a stock of goods which have an economic value. For an inventory model, demand is taken as either timedependent or constant. But, in reality, demand is very much associated with the selling price. When the selling

Keywords. Economic Order Quantity, price-sensitive demand, shortage, default risk, deterioration, inventory management, optimization.

1 Department of Applied Mathematics with Oceanology and Computer Programming Vidyasagar University, Midnapore 721102, West Bengal, India.

2 Department of Mathematics and Statistics, Kingston School of Management and Science, Barasat, Kolkata 700126, West Bengal, India.

3 Faculty of Engineering Management Poznan University of Technology, ul. Jacka Rychlewskiego 2, 60-965 Poznan, Poland.

4 Institute of Applied Mathematics, Middle East Technical University, 06800 Ankara, Turkey.

5 Department of Industrial Engineering, Kharazmi University, Tehran, Iran.

* Corresponding author: sankroy2006@gmail.com 
price is low, the demand is higher, and the demand is low when the selling price is higher. Nowadays, business is done under competitive market scenarios. The competitors must have better cost structures. They reduce the prices of the goods to attract more customers. Customers do not want to spend more money for similar products or the same quality of products. For example, the prices of a cotton shirt of same quality are $\$ 10$ and $\$ 15$ in different shops. Customers prefer the shirt which costs $\$ 10$. Customers always look for better products at low prices (except for some very exquisite products, or when they feel insecure about the quality of some goods). Retailers sometimes offer a discounted price to attract more customers. So, price discount on particular items has an interesting impact on consumers, which attracts us to formulate our work.

Shortage means an inadequacy of a stock of a certain commodity to meet the demand at a particular time [18]. In reality, the occurrence of shortage in inventory is a vital situation. During shortage period, customers react differently. Some needy or impatient customers leave the system and buy from other stores. Some customers wait for an upcoming lot and remain in the system. Shortage may happen due to the elimination of the worst products. Shortages are very important, especially for any model that deals with permissible delay in payments. Indeed, shortage may result a cancellation of order and in heavy losses in sale. Shortage can generate a profit obtained from delay in payment. Partial backlogging is a process that offers the customer to stay in that inventory system. Partial backlogging is highly dependent on the length of the delivery interval while complete backlogging is applicable for a monopolistic market. So, partial backlogging during a shortage period is an important tool in inventory control.

Default occurs when a firm's cash flow is insufficient to cover its debt service costs as a principal payment. Default risk increases when a firm's average cash flow level shifts down or its cash flow volatility increases. Default risk is a possibility that an individual will be unable to make the required payments on his or her debt obligation. If the credit period is too short, then the buyer is unable to pay back, which increases the default risk. If the credit period is longer, then this helps the buyer to make the payment and to decrease the default risk. By incorporating default risk, this paper tries to provide an impact on the literature with respect to maximum profit.

Deterioration is described as damage, decay, spoilage, evaporation, vaporization, degradation, collapse, pinch or loss of utility [18]. The rate of deterioration is negligible for items like toys, hardware, steel, glassware, etc. The deterioration is high for fruits, alcohol, blood, vegetables, medicine, etc. Deterioration is a process that prevents the items from being used under their original conditions. Various physical features of deteriorating items decay over time. The deterioration rate may decrease with the use of technology. Thus, involvement of deterioration is an important tool in the determination of an inventory and must be taken into consideration.

The main motivations of our paper are as follows:

(a) To introduce an Economic Order Quantity (EOQ) model for finding the maximum profit.

(b) In general, demand is inversely affected by selling price. Not only that, if a retailer offered a credit-period, demand for such items increased hugely. By considering all these criteria, in this paper, we assume that demand is selling price and credit-period dependent.

(c) Default risk is allowed to ensure a more realistic view.

(d) Deterioration is included and its depends on time.

(e) Shortage is allowed to be considered in a more realistic sense.

(f) Partial backlogging is permitted during the shortage period for those who are interested to wait for backordered items.

This paper extends the work of Wu et al. [38] by considering (i) credit-period and selling price dependent demand, (ii) shortages, (iii) partial backlogging, (iv) down stream trade credit period offered by the retailer. Finally, this paper shows a higher profit and a lower cycle time than the paper of Wu et al. [38].

The rest of the paper is organized as follows: In Section 2, a literature review of the paper is presented. In Sections 3.1 and 3.2, we describe the notations and assumptions of the formulated model, respectively. In Section 4, a mathematical formulation of the model is developed. Section 5 deals with the solution procedure of the formulated model. A numerical example is solved at Section 6. Section 7 offers a sensitivity analysis 
with respect to various model parameters. Finally, conclusions and future directions of research are provided in Section 8.

\section{Motivation AND REVIEW ON RESEARCH}

Demand is very much associated with the selling price. Related to this context, some researchers published their works based on demand that depends on the selling price. Teng et al. [34] generalized traditional constant demand to non-decreasing demand. San-José et al. [28] explored an inventory system with demand dependent on price and time. Sharma et al. [31] depicted an EPQ model with price-sensitive demand for deteriorating items, production rate depending on demand, and shortages being partially backlogged. Pal et al. [16] described a twoechelon competitive integrated supply chain model with price- and credit- period dependent demand. Barman et al. [3] studied a back-ordered inventory model with inflation in a cloudy-fuzzy environment. Saxena et al. [29] explored a green supply chain model of vendor and buyer for re-manufacturing. Navarro et al. [15] discussed a collaborative EPQ inventory model for a three-echelon supply chain with multiple products considering the effect of marketing effort on demand. Moghdani et al. [14] explored multi-item fuzzy economic production quantity model with multiple deliveries. Lotfi et al. [9] discussed the two-period newsvendor problem with interdependent demand. Mehrjerdi and Lotfi [13] explored a sustainable closed-loop supply chain with efficiency and resilience systematic framework. Taleizadeh et al. [32] formulated production models of multiple products using a single machine under quality screening and reworking policies. Karimian et al. [7] discussed a geometric programming approach for a vendor managed EPQ model with multi retailer and multi-item. Manna et al. [12] investigated the impact of carbon emission on imperfect production inventory system with advance payment. Chain-Huei Ho [6] investigated the optimal integrated inventory policy with price-and-credit-linked demand under two-level trade credit. In this paper, demand is taken as a negative exponential power of selling price and some positive exponential of credit period.

Items are partial backlogged during the shortage period for those who are interested to wait for the next lot. Chowdhury et al. [5] considered an order-level inventory model with time-quadratic demand and partial backlogging. Rastogi et al. [25] designed an inventory model for two-warehouse system under partial backlogging with price-dependent demand. Rastogi et al. [24] described an inventory model with price-sensitive demand, and variable holding cost under partial backlogging. Pervin et al. [19] initiated an inventory model with shortage under time-dependent demand and stochastic deterioration. Taleizadeh et al. [33] discussed the replenishment of imperfect items in an EOQ inventory model with partial back-ordering.

A credit period is the time frame between when a customer purchases products and when the customer's payment is due. In other words, this is the amount of time on which a customer has to pay for the product. $\mathrm{Wu}$ et al. [38] analysed an optimal credit period and lot size by taking into account demand dependence on a delayed payment time with default risk for deteriorating items with expiration date. Teng et al. [35] inquired the optimal trade credit and lot-size policies addressing the demand and default risk sensitive to the credit period with a learning curve in the production costs. Zhang et al. [39] explored supply chain coordination with trade credit and quantity discount incorporating default risk. Lou et al. [10] investigated about optimal trade credit and order quantity when a trade-credit impacts on the demand rate and the default risk. Mahata et al. [11] discussed retailer's optimal credit period and cycle time for deteriorating items with stock-sensitive and credit-sensitive demand, incorporating default risk. Pervin et al. [20] designed an integrated inventory model with variable holding cost under two levels of trade-credit policy. Pervin et al. [17] investigated an inventory model with declining demand market for deteriorating items under a trade-credit policy. Roy et al. [27] inquired a two-warehouse probabilistic model with price discount on backorders under two levels of trade credit policy. Pervin et al. [23] discussed an integrated vendor-buyer model with quadratic demand under inspection policy. In this paper, we consider default risk which is sensitive to credit period.

Deterioration is a natural phenomenon and it depends on time. During recent years, many articles on deteriorating inventory models appeared in various journals. Wu et al. [37] investigated the lot sizing policies for deteriorating items with expiration dates and partial trade credit to a credit risk customer by addressing 
TABLE 1. Contributions of different authors related to inventory model.

\begin{tabular}{|c|c|c|c|c|c|c|}
\hline Author(s) & $\begin{array}{l}\text { Shortages } \\
\text { policy }\end{array}$ & Deterioration & $\begin{array}{l}\text { Permissible } \\
\text { delay in } \\
\text { payment }\end{array}$ & $\begin{array}{l}\text { Price } \\
\text { sensitive } \\
\text { demand }\end{array}$ & $\begin{array}{l}\text { Default } \\
\text { risk }\end{array}$ & $\begin{array}{l}\text { Credit- } \\
\text { period } \\
\text { sensitive } \\
\text { demand }\end{array}$ \\
\hline $\begin{array}{l}\text { Chain- } \\
\text { Huei Ho } \\
{[6]}\end{array}$ & & & $\sqrt{ }$ & $\sqrt{ }$ & & $\sqrt{ }$ \\
\hline $\begin{array}{l}\text { Teng et al. } \\
{[34]}\end{array}$ & & & $\sqrt{ }$ & & & \\
\hline $\begin{array}{l}\text { Wu et al. } \\
{[38]}\end{array}$ & & $\sqrt{ }$ & $\sqrt{ }$ & & $\sqrt{ }$ & \\
\hline $\begin{array}{l}\text { Zhang } \\
\text { et al. [39] }\end{array}$ & & & $\sqrt{ }$ & & $\sqrt{ }$ & \\
\hline $\begin{array}{l}\text { Mahata } \\
\text { et al. }[11]\end{array}$ & & $\sqrt{ }$ & $\sqrt{ }$ & & $\sqrt{ }$ & \\
\hline $\begin{array}{l}\text { Pal et al. } \\
{[16]}\end{array}$ & & & $\sqrt{ }$ & $\sqrt{ }$ & & \\
\hline Teng et al. & $\sqrt{ }$ & $\sqrt{ }$ & & & & \\
\hline $\begin{array}{l}\text { Lashgari } \\
\text { et al. }[8]\end{array}$ & $\sqrt{ }$ & $\sqrt{ }$ & $\sqrt{ }$ & & & \\
\hline $\begin{array}{l}\text { Rastogi } \\
\text { et al. }[24]\end{array}$ & $\sqrt{ }$ & & & $\sqrt{ }$ & & \\
\hline $\begin{array}{l}\text { Pervin } \\
\text { et al. }[21]\end{array}$ & $\sqrt{ }$ & $\sqrt{ }$ & & $\sqrt{ }$ & & \\
\hline This Work & $\sqrt{ }$ & $\sqrt{ }$ & $\sqrt{ }$ & $\sqrt{ }$ & $\sqrt{ }$ & $\sqrt{ }$ \\
\hline
\end{tabular}

demand dependence on trade credit and default risk, related to credit period. Pervin et al. [18] designed a two-echelon inventory model with stock-dependent demand and variable holding cost for deteriorating items. Pervin et al. [21] investigated a deteriorating inventory with preservation technology under price-sensitive and stock-sensitive demand. Roy et al. [26] investigated a deteriorating model with inspection policy under trade credit and variable demand. Pervin et al. [22] formulated a multi-item two-echelon deteriorating inventory model with price-dependent and stock-dependent demand. Lashgari [8] et al. studied an inventory control problem for deteriorating items with back-ordering and financial considerations under two levels of trade credit linked to order quantity. In this paper, the deterioration rate is time dependent. Teng et al. [36] explored inventory lotsize policies for deteriorating items with expiration dates and advance payments. In this paper time dependent deteriorating rate is considered.

So, after reviewing the literature mentioned above, a comparison table showing different inventory problem is depicted in Table 1. After reviewing the previous work, this paper extends the Wu et al.'s model [38] by considering credit-period and selling price dependent demand, allowing shortages, partial backlogging of items and a down-stream trade-credit period offered by the retailer.

\section{Notations And ASSUmptions}

The notations and assumptions which are used in this paper are given as follows. 


\subsection{Notations}

\section{Parameters}

$A$ : Unit ordering cost per item per order;

$h$ : Unit holding cost per item per unit time;

$c$ : Unit purchasing cost per item;

$s:$ Unit selling price per item, $s>c$;

$D$ : Market demand rate for the item increased with the customer credit-period $n$ and decreased with the retailer's selling price $s$ which is given by $\alpha n^{x} / s^{\beta}$, where $\alpha$ is the scaling parameter, $x>0$ is a constant, and $\beta$ is a price-elasticity coefficient;

$I_{1}(t)$ : Inventory level during non-production period;

$I_{2}(t)$ : Inventory level during shortage period;

$Q_{1}$ : Retailer inventory level;

$Q_{2}$ : Back order quantity;

$Q:$ Order quantity, $Q=Q_{1}+Q_{2}$;

$l_{1}$ : Unit shortage cost per item per unit time;

$l_{2}$ : Unit lost sale cost per item per unit time;

$\gamma$ : Backlogging rate (partial);

$I_{c}:$ Interest charged;

$I_{e}:$ Interest earned;

\section{Decision variables}

$\beta$ : Price elasticity parameter;

$n$ : Credit period in years offered by the retailer to his/her customer;

$T_{1}$ : Beginning of shortage period;

$T$ : Length of cycle time;

\section{Objectives}

$\mathrm{TP}_{1}$ : Total profit of the system per unit time when $T>n$; $\mathrm{TP}_{2}$ : Total profit of the system per unit time when $T<n$.

\subsection{Assumptions}

3.2.1 The time horizon is infinite, so as to reflect the long-term cooperative relationships.

3.2.2 If the credit period to the customer is longer, then the default risk to the retailer is higher. For simplicity, the rate of the default risk given to the credit period $n$ offered by the retailer is $F(n)=1-e^{-b n}$, where $b>0$.

3.2.3 Deterioration rate is a function of time and $\theta t$ is the deterioration rate, where $\theta \in[0,1]$.

\section{Mathematical Formulation}

In this paper, it is assumed that an inventory of $Q_{1}$ units of the items has been taken at the beginning of each cycle of length $T$. It is also assumed that due to demand and deterioration, the inventory level becomes 0 at time $T_{1}$. Hence, the interval $\left[T_{1}, T\right]$ is the period of shortage. In between the shortage interval, the unsatisfied demand is backlogged at a rate of $\gamma$. Thus, the instantaneous inventory level at any time $t$ in $[0, T]$ is governed by the differential equations (4.1) and (4.2):

$$
\begin{aligned}
\frac{\mathrm{d} I_{1}(t)}{\mathrm{d} t}+\theta t I_{1}(t) & =-\frac{\alpha n^{x}}{s^{\beta}}, \quad 0 \leq t \leq T_{1} \quad \text { with } I_{1}\left(T_{1}\right)=0, \\
\frac{\mathrm{d} I_{2}(t)}{\mathrm{d} t} & =-\frac{\gamma \alpha n^{x}}{s^{\beta}}, \quad T_{1} \leq t \leq T \quad \text { with } I_{2}\left(T_{1}\right)=0 .
\end{aligned}
$$




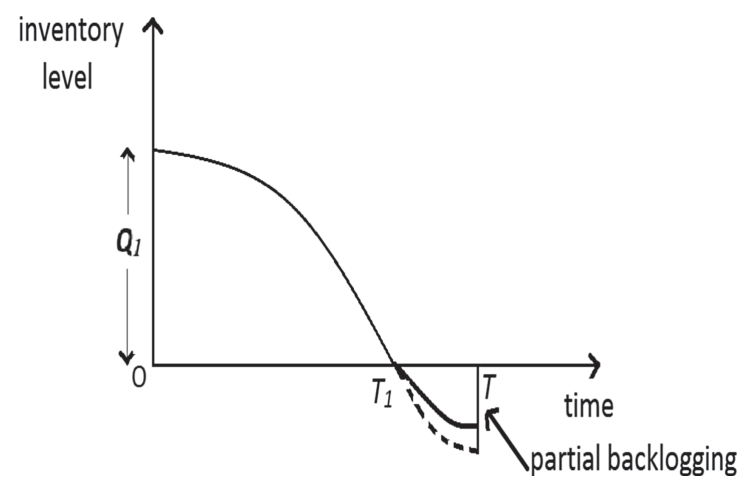

FiguRE 1. Graphical representation of the proposed inventory model.

The solution of terminal value problem (4.1) is, neglecting higher orders of $\theta$ :

$$
I_{1}(t)=\frac{1}{e^{\frac{\theta t^{2}}{2}}} \frac{\alpha n^{x}}{s^{\beta}}\left(T_{1}+\frac{\theta T_{1}^{3}}{6}-t-\frac{\theta t^{3}}{6}\right), 0 \leq t \leq T_{1} .
$$

The solution of initial value problem (4.2) is:

$$
I_{2}(t)=\frac{\gamma \alpha n^{x}}{s^{\beta}}\left(T_{1}-t\right), \quad T_{1} \leq t \leq T .
$$

Figure 1 graphically displays our proposed model.

Here, $Q_{1}=I_{1}(0)=\frac{\alpha n^{x}}{s^{\beta}}\left(T_{1}+\frac{\theta T_{1}^{3}}{6}\right)$ and $Q_{2}=\frac{\alpha n^{x}}{s^{\beta}} \gamma\left(T-T_{1}\right)$.

To calculate the profit function, we calculate the following terms:

(1) Ordering cost $=\frac{A}{T}$;

(2) Holding cost $=\frac{h}{T} \int_{0}^{T_{1}} I_{1}(t) \mathrm{d} t=\frac{h}{T} \frac{\alpha n^{x}}{s^{\beta}}\left(\frac{T_{1}^{2}}{2}+\frac{\theta T_{1}^{4}}{8}\right)$;

(3) Shortage cost $=l_{1} \gamma \int_{T_{1}}^{T} D(t) \mathrm{d} t=l_{1} \gamma \frac{\alpha n^{x}}{s^{\beta}}\left(T-T_{1}\right)$;

(4) Lost-sale cost $=l_{2} \int_{T_{1}}^{T}(1-\gamma) D(t) \mathrm{d} t=l_{2}(1-\gamma)\left(T-T_{1}\right) \frac{\alpha n^{x}}{s^{\beta}}$;

(5) Unit deteriorating cost $=\left(I_{1}(0)-\int_{0}^{T_{1}} D(t) \mathrm{d} t\right) \frac{c}{T}=\frac{c \theta T_{1}^{3}}{6 T} \frac{\alpha n^{x}}{s^{\beta}}$;

(6) Unit purchasing cost $=\frac{c Q}{T}=\frac{c}{T}\left(T_{1}+\frac{\theta T_{1}^{3}}{6}+\gamma T-\gamma T_{1}\right) \frac{\alpha n^{x}}{s^{\beta}}$;

(7) Sales revenue considering the default risk $=\frac{s(1-F(n))}{T} \frac{\alpha n^{x}}{s^{\beta}}$.

(8a) $T>n$, when the credit period is shorter than the replenishment cycle time $T$, the retailer begins to earn interest with rate $I_{e}$ in $[n, T]$. Hence, the total interest earned by the retailer is $=s I_{e}(T-n) \alpha n^{x} / T s^{\beta}$.

(8b) The retailer loses some interest in the period $[0, n]$ at the rate of $I_{c}$. Hence, the total interest lost by retailer is $n s I_{c} \alpha n^{x} / T s^{\beta}$.

(9a) $T<n$, when credit period is greater than the replenishment time $T$, there is no interest earn by the retailer. Therefore, the interest earned by retailer in this case is zero.

(9b) Retailer loses some interest in this case. The retailer loses interest up to time $n$ at the rate of $I_{c}$. Here, the interest loss is $s I_{c} \alpha n^{x+1}(n-T) / T s^{\beta}$.

Hence, the total profit can be defined as follows:

Total profit $=$ sales revenue considering default risk + interest earn - interest lost

- purchasing cost - holding cost - deterioration cost - shortage cost

- lost sale cost - ordering cost. 
Now, inserting the values of the respective costs into the total profit, we obtain two types of profit functions:

$$
\begin{aligned}
\mathrm{TP}_{1}\left(T, n, T_{1}, \beta\right)= & \frac{s e^{-b n}}{T} \frac{\alpha n^{x}}{s^{\beta}}+\frac{s I_{e}(T-n)}{T} \frac{\alpha n^{x}}{s^{\beta}}-\frac{n s I_{c}}{T} \frac{\alpha n^{x}}{s^{\beta}} \\
& -\frac{c}{T}\left(T_{1}+\frac{\theta T_{1}^{3}}{6}+\gamma T-\gamma T_{1}\right) \frac{\alpha n^{x}}{s^{\beta}}-\frac{c \theta T_{1}^{3}}{6 T} \frac{\alpha n^{x}}{s^{\beta}}-\frac{A}{T} \\
& -l_{2}(1-\gamma)\left(T-T_{1}\right) \frac{\alpha n^{x}}{s^{\beta}}-l_{1} \gamma \frac{\alpha n^{x}}{s^{\beta}}\left(T-T_{1}\right) \\
& -\frac{h}{T} \frac{\alpha n^{x}}{s^{\beta}}\left(\frac{T_{1}^{2}}{2}+\frac{\theta T_{1}^{4}}{8}\right), \quad T>n ; \\
\operatorname{TP}_{2}\left(T, n, T_{1}, \beta\right)= & \frac{s e^{-b n}}{T} \frac{\alpha n^{x}}{s^{\beta}}-\frac{s I_{c} \alpha n^{x+1}(n-T)}{T s^{\beta}}-\frac{c}{T}\left(T_{1}+\frac{\theta T_{1}^{3}}{6}+\gamma T-\gamma T_{1}\right) \frac{\alpha n^{x}}{s^{\beta}} \\
& -\frac{c \theta T_{1}^{3}}{6 T} \frac{\alpha n^{x}}{s^{\beta}}-l_{2}(1-\gamma)\left(T-T_{1}\right) \frac{\alpha n^{x}}{s^{\beta}}-l_{1} \gamma \frac{\alpha n^{x}}{s^{\beta}}\left(T-T_{1}\right) \\
& -\frac{h}{T} \frac{\alpha n^{x}}{s^{\beta}}\left(\frac{T_{1}^{2}}{2}+\frac{\theta T_{1}^{4}}{8}\right)-\frac{A}{T}, \quad T<n .
\end{aligned}
$$

\section{Solution PROCEDURE}

To solve the formulated mathematical model, we use the existing results of Concave Fractional Programming. We apply the results from Bardhan et al. [2] which states the following results.

Definition 5.1. A pseudoconvex function is a function which behaves like a convex function when its local minima is found. In other words, a differentiable function which has a positive directional derivative in any direction when the function is increasing, is called a pseudoconvex function. A negative of the pseudoconvex function is called a pseudoconcave function.

Lemma 5.2. A real-valued function $s(x)=p(x) / q(x)$ is strictly pseudoconcave, if $p$ is nonnegative, differentiable and strictly concave, and $q$ is positive, differentiable and convex.

Referring to Cambini and Martein [4] and Schaible [30], we state the following result.

Lemma 5.3. In a concave fractional program, there exists a unique global optimal solution for a strictly pseudoconcave function. In a differentiable concave fractional program, a solution of the Karush-Kuhn-Tucker (KKT) conditions is a global maximum.

Now, we develop some propositions and prove them to solve our previously formulated mathematical model. To prove the propositions, we use an important existing theorem of function of several real variables.

Implicit Function Theorem. Let $F(x, y, z)$ be a continuously differentiable function with continuous partial derivatives defined on an open set $S_{1}$ containing the point $P_{1}=\left(x_{0}, y_{0}, z_{0}\right)$ so that $F\left(x_{0}, y_{0}, z_{0}\right)=0$. If $\partial F / \partial z \neq 0$ at $P_{1}$, then there exists a neighborhood $R$ around $\left(x_{0}, y_{0}\right)$ such that for any $(x, y)$ in $R$, there is a unique $Z=z(x, y)$ such that $F\left(x_{0}, y_{0}, z(x, y)\right)=0$.

Let us now construct our results and prove them by using the above all.

Result 1. The profit function $\operatorname{TP}_{1}\left(T, T_{1}, n, \beta\right)$ is a strictly pseudoconcave function in $T$ and there exists a unique maximum solution, named as $T^{*}$, for any $T_{1}, n, \beta$. 
Proof (computer supported). Let us define nonnegative function $p_{1}(t)$ and $q_{1}(t)$ for any given $T_{1}, n, \beta$ :

$$
\begin{aligned}
p_{1}(T)= & \frac{\alpha n^{x}}{s^{\beta}}\left(s e^{-b n}+s I_{e}(T-n)-n s I_{c}-c\left(T_{1}+\frac{\theta T_{1}^{3}}{6}+\gamma T-\gamma T_{1}\right)-\frac{c \theta T_{1}^{3}}{6}\right. \\
& \left.-l_{2}(1-\gamma)\left(T^{2}-T_{1} T\right)-l_{1} \gamma\left(T^{2}-T_{1} T\right)-h\left(\frac{T_{1}^{2}}{2}+\frac{\theta T_{1}^{4}}{4}\right)\right)-A,
\end{aligned}
$$

and $q_{1}(T)=T$.

Now, taking the first- and second-order partial derivatives of $p_{1}(T)$, with respect to $T$, we get

$$
\begin{aligned}
\frac{\partial p_{1}(T)}{\partial T} & =\frac{\alpha n^{x}}{s^{\beta}}\left(s I_{e}-c \gamma-l_{2}(1-\gamma)\left(2 T-T_{1}\right)-l_{1} \gamma\left(2 T-T_{1}\right)\right), \\
\frac{\partial^{2} p_{1}(T)}{\partial T^{2}} & =\frac{\alpha n^{x}}{s^{\beta}}\left(-2 l_{2}(1-\gamma)-2 l_{1} \gamma\right) .
\end{aligned}
$$

We see by the use of Mathematica that

$$
\frac{\partial^{2} p_{1}(T)}{\partial T^{2}}<0, \quad \forall T>0
$$

Here, $\mathrm{TP}_{1}\left(T, T_{1}, n, \beta\right)$ is continuously differentiable real function; therefore, there exists a continuous gradient of the function $\operatorname{TP}_{1}\left(T, T_{1}, n, \beta\right)$. Therefore, by computational verification (including usage of the Intermediate Value Theorem) we demonstrate the existence of one zero point of $F$ (i.e., $F=0$ is fulfilled). By Implicit Function Theorem, there exists a solution going through the point $\left(T_{0}, \hat{T}_{1}, n_{0}, \beta_{0}\right)$ of the problem $F=0$ with $F=\left.\frac{\partial \mathrm{TP}_{1}}{\partial T}\right|_{\left(T_{1}, n, \beta\right)}$, a local solution, not vanishing at the point solution, locally unique, and with a local parametrization, called as implicit function, $T^{*}=T^{*}\left(T_{1}, n, \beta\right)$.

Here, $p_{1}(T)$ is differentiable and strictly concave, and $q_{1}(T)$ is positive, differentiable and convex. Hence, by Lemma 5.2 we say that

$$
\operatorname{TP}_{1}\left(T, T_{1}, n, \beta\right)=\frac{p_{1}(T)}{q_{1}(T)}<0
$$

is a pseudoconcave function in $T$ for any $T_{1}, n, \beta$. Because the function $p_{1}(T)$ is non-negative, differentiable and strictly concave; $q_{1}(T)$ is positive, differentiable and convex. So, by Lemma 5.2 the function $\operatorname{TP}_{1}\left(T, T_{1}, n, \beta\right)$ is strictly pseudoconcave.

Now, to find the optimal implicit function $T^{*}\left(T_{1}, n, \beta\right)$, explicitly, let us take the first-order partial derivative of $\operatorname{TP}_{1}\left(T, T_{1}, n, \beta\right)$ with respect to $T$, for equating that derivative with respect to $T$, we compute it first:

$$
\begin{aligned}
\frac{\partial \mathrm{TP}_{1}}{\partial T}= & \frac{\alpha n^{x}}{s^{\beta}}\left(-\frac{s e^{-b n}}{T^{2}}-\frac{s I_{e}(T-n)}{T^{2}}+\frac{s I_{e}}{T}+\frac{n s I_{c}}{T^{2}}+\frac{h}{T^{2}}\left(\frac{T_{1}^{2}}{2}+\frac{\theta T_{1}^{4}}{8}\right)-l_{1} \gamma\right. \\
& \left.-l_{2}(1-\gamma)+\frac{\theta T_{1}^{3} c}{6 T^{2}}+\frac{c}{T^{2}}\left(T+\frac{\theta T_{1}^{3}}{6}+\gamma T-\gamma T_{1}\right)-\frac{c}{T}(1+\gamma)\right)+\frac{A}{T^{2}} .
\end{aligned}
$$

Now, by employing computational power and by applying Intermediate Value Theorem to the Lagrangian system, with respect to $T$, we can conclude the existence of of a solution of the KKT condition. Then by using Lemma 5.3, we say that there exists a unique global maximum solution, $T^{*}\left(T_{1}, n, \beta\right)$. This proves the result.

Result 2. For any feasible $T, n, \beta$, there exists a $T_{1}^{*}$ that maximizes the profit function $\operatorname{TP}_{1}\left(T, T_{1}, n, \beta\right)$. 
Proof (computer supported). The first- and second-order partial derivatives with respect to $T_{1}$ are:

$$
\begin{aligned}
\frac{\partial \mathrm{TP}_{1}\left(T, n, T_{1}, \beta\right)}{\partial T_{1}} & =\frac{\alpha n^{x}}{s^{\beta}}\left(-\frac{h}{T}\left(T_{1}+\frac{\theta T_{1}^{3}}{2}\right)+l_{1} \gamma+l_{2}(1-\gamma)+\frac{\theta T_{1}^{2} c}{2 T}-\frac{c}{T}\left(\frac{\theta T_{1}}{2}-\gamma\right)\right), \\
\frac{\partial^{2} \mathrm{TP}_{1}\left(T, n, T_{1}, \beta\right)}{\partial T_{1}^{2}} & =\frac{\alpha n^{x}}{s^{\beta}}\left(-\frac{h}{T}\left(1+\frac{3 \theta T_{1}^{2}}{2}\right)+\frac{\theta T_{1} c}{T}-\frac{c \theta}{2 T}\right) .
\end{aligned}
$$

Now, we check with the help of Mathematica for any feasible value of $T, n, \beta$ that

$$
\frac{\partial^{2} \mathrm{TP}_{1}\left(T, n, T_{1}, \beta\right)}{\partial T_{1}^{2}}<0
$$

Therefore, it is concluded that $\operatorname{TP}\left(T, T_{1}^{*}, n, \beta\right)$ is a concave function with respect to $T_{1}^{*}$. The problem is a concave fractional program. Then, we can say from Lemma 5.3 and Implicit Function Theorem, that $\operatorname{TP}\left(T, T_{1}^{*}, n, \beta\right)$ attains a local maximum which is the global maximum also due to the pseudoconcavity of $\operatorname{TP}\left(T, T_{1}^{*}, n, \beta\right)$. Therefore, it is sufficient to establish the KKT conditions. This completes the proof of the result.

Result 3. For any feasible $T, T_{1}, \beta$ there exists an $n^{*}$ that maximizes the profit function $\operatorname{TP}_{1}\left(T, T_{1}, n, \beta\right)$.

Proof (computer supported). The first- and second-order partial derivatives with respect to $n$ are:

$$
\begin{aligned}
\frac{\partial \mathrm{TP}_{1}\left(T, n, T_{1}, \beta\right)}{\partial n}= & \frac{x \alpha n^{x-1}}{s^{\beta}}\left(-\frac{h}{T}\left(\frac{T_{1}^{2}}{2}+\frac{\theta T_{1}^{4}}{8}\right)-l_{1} \gamma\left(T-T_{1}\right)-l_{2}(1-\gamma)\left(T-T_{1}\right)-\frac{\theta T_{1}^{3} c}{6 T}\right. \\
& \left.-\frac{c}{T}\left(T+\frac{\theta T_{1}^{3}}{6}+\gamma T-\gamma T_{1}\right)+\frac{s e^{-b n}}{T}-\frac{n s I_{c}}{T}+\frac{s I_{e}(T-n)}{T}\right)+\frac{\alpha n^{x}}{s^{\beta}} \\
& \times\left(-\frac{e^{-b n} b s}{T}-\frac{s I_{c}}{T}-\frac{s I_{e}}{T}\right), \\
\frac{\partial^{2} \operatorname{TP}_{1}\left(T, n, T_{1}, \beta\right)}{\partial n^{2}}= & \frac{x(x-1) \alpha n^{x-2}}{s^{\beta}}\left(-\frac{h}{T}\left(\frac{T_{1}^{2}}{2}+\frac{\theta T_{1}^{4}}{8}\right)-l_{1} \gamma\left(T-T_{1}\right)-l_{2}(1-\gamma)\left(T-T_{1}\right)\right. \\
& \left.-\frac{\theta T_{1}^{3} c}{6 T}-\frac{c}{T}\left(T+\frac{\theta T_{1}^{3}}{6}+\gamma T-\gamma T_{1}\right)+\frac{s e^{-b n}}{T}-\frac{n s I_{c}}{T}+\frac{s I_{e}(T-n)}{T}\right) \\
& +\frac{2 x \alpha n^{x-1}}{s^{\beta}}\left(-\frac{s b e^{-b n}}{T}-\frac{s I_{c}}{T}-\frac{s I_{e}}{T}\right)+\frac{\alpha n^{x}}{s^{\beta}} \frac{b^{2} s e^{-b n}}{T}
\end{aligned}
$$

Now, we check with the help of Mathematica for any feasible value of $T, T_{1}, \beta$ that

$$
\frac{\partial^{2} \mathrm{TP}_{1}\left(T, n, T_{1}, \beta\right)}{\partial n^{2}}<0 .
$$

Therefore, it is concluded that $\operatorname{TP}_{1}\left(T, T_{1}, n, \beta\right)$ is a concave function with respect to $n^{*}$. The problem is a concave fractional program. Then, we can say that from Lemma 5.3 and Implicit Function Theorem, that $\mathrm{TP}_{1}\left(T, T_{1}, n^{*}, \beta\right)$ attains a local maximum which is the global maximum also due to the pseudoconcavity of $\mathrm{TP}_{1}\left(T, T_{1}, n^{*}, \beta\right)$. Therefore, it is sufficient to establish the KKT conditions. This completes the proof of the result.

Result 4. The profit function $\operatorname{TP}_{1}\left(T, T_{1}, n, \beta\right)$ is a strictly pseudoconcave function in $\beta$ and there exists a unique maximum solution, named as $\beta^{*}$ for any $T, T_{1}, n$. 
Proof (computer supported). Let us define nonnegative function $p_{2}(t)$ and $q_{2}(t)$ for any given $T, T_{1}, n$.

$$
\begin{aligned}
p_{2}(\beta)= & \alpha n^{x}\left(\frac{s e^{-b n}}{T}+\frac{s I_{e}(T-n)}{T}-\frac{n s I_{c}}{T}-\frac{c}{T}\left(T_{1}+\frac{\theta T_{1}^{3}}{6}+\gamma T-\gamma T_{1}\right)-\frac{c \theta T_{1}^{3}}{6 T}\right. \\
& \left.-l_{2}(1-\gamma)\left(T-T_{1}\right)-l_{1} \gamma\left(T-T_{1}\right)-\frac{h}{T}\left(\frac{T_{1}^{2}}{2}+\frac{\theta T_{1}^{4}}{8}\right)\right)-\frac{A s^{\beta}}{T},
\end{aligned}
$$

and $q_{2}(\beta)=s^{\beta}$.

Now taking the first- and second-order partial derivatives of $p_{2}(\beta)$, with respect to $\beta$, we get

$$
\frac{\partial p_{2}(\beta)}{\partial \beta}=-\frac{A s^{\beta} \ln s}{T}
$$

and

$$
\frac{\partial^{2} p_{2}(\beta)}{\partial \beta^{2}}=-\frac{A s^{\beta}(\ln s)^{2}}{T} .
$$

We see by the use of Mathematica that $\partial^{2} p_{2}(\beta) / \partial \beta^{2}<0, \forall \beta>0$.

Here, $\operatorname{TP}_{1}\left(T, T_{1}, n, \beta\right)$ is continuously differentiable real function; hence, there exists a continuous gradient of the function $\operatorname{TP}_{1}\left(T, T_{1}, n, \beta\right)$. Therefore, by computational verification (including usage of the Intermediate Value Theorem) we demonstrate the existence of one zero point of $F$ (i.e., $F=0$ is fulfilled). By Implicit Function Theorem, there exists a point solution going through the point $\left(T_{0}, \hat{T}_{1}, n_{0}, \beta_{0}\right)$ of the problem $F=0$ with $F=\left.\frac{\partial \mathrm{TP}_{1}}{\partial \beta}\right|_{\left(T, T_{1}, n\right)}$, a local solution, not vanishing at the point solution, locally unique, and with a local parametrization, called as implicit function, $\beta^{*}=\beta^{*}\left(T, T_{1}, n\right)$.

Here, $p_{2}(\beta)$ is differentiable and strictly concave, and $q_{2}(\beta)$ is positive, differentiable and convex. Hence by Lemma 5.2 we say that

$$
\operatorname{TP}_{1}\left(T, T_{1}, n, \beta\right)=\frac{p_{2}(\beta)}{q_{2}(\beta)}<0
$$

is a pseudoconcave function in $\beta$ for any $T, T_{1}, n$. Because $p_{2}(\beta)$ and $q_{2}(\beta)$ satisfied the conditions of Lemma 5.2 and hence $\operatorname{TP}_{1}\left(T, T_{1}, n, \beta\right)$ is pseudoconcave function. Now, to find the optimal implicit function $\beta^{*}$, explicitly, let us take the first-order partial derivative of $\operatorname{TP}_{1}\left(T, T_{1}, n, \beta\right)$ with respect to $\beta$, for equating that derivative with respect to $\beta$, we compute first:

$$
\begin{aligned}
\frac{\partial \mathrm{TP}_{1}\left(T, n, T_{1}, \beta\right)}{\partial \beta}= & \frac{\alpha n^{x}}{s^{\beta}} \ln S\left(-\frac{h}{T}\left(\frac{T_{1}^{2}}{2}+\frac{\theta T_{1}^{4}}{8}\right)-l_{1} \gamma\left(T-T_{1}\right)-l_{2}(1-\gamma)\left(T-T_{1}\right)\right. \\
& \left.-\frac{\theta T_{1}^{3} c}{6 T}-\frac{c}{T}\left(T+\frac{\theta T_{1}^{3}}{6}+\gamma T-\gamma T_{1}\right)+\frac{s e^{-b n}}{T}-\frac{s I_{c} n}{T}+\frac{s I_{e}(T-n)}{T}\right) .
\end{aligned}
$$

Now by employing computational power and by applying Intermediate Value Theorem to the Lagrangian system, with respect to $\beta$, we can conclude the existence of a solution of the KKT conditions. Then, by Lemma 5.3, we say that there exists a unique global maximum solution, $\beta^{*}$. This proves the result.

A similar procedure which is described for $\mathrm{TP}_{1}$ can also be applied to $\mathrm{TP}_{2}$.

\section{Algorithm}

Step 1. Initialize system parameters.

Step 2. Calculate $\frac{\partial \mathrm{TP}_{i}}{\partial T}, \frac{\partial \mathrm{TP}_{i}}{\partial T_{1}}, \frac{\partial \mathrm{TP}_{i}}{\partial \beta}, \frac{\partial \mathrm{TP}_{i}}{\partial n}, i=1,2$.

Step 3. Solve $\frac{\partial \mathrm{TP}_{i}}{\partial T}=0, \frac{\partial \mathrm{TP}_{i}}{\partial T_{1}}=0, \frac{\partial \mathrm{TP}_{i}}{\partial \beta}=0, \frac{\partial \mathrm{TP}_{i}}{\partial n}=0, i=1,2$. 


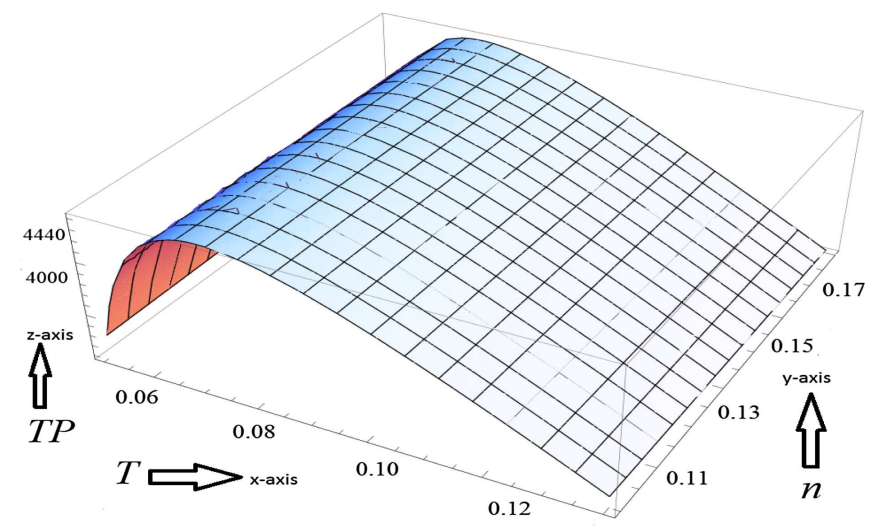

FIgURE 2. Graphical representation to display concavity of the profit. The figure depicts $T, n$ and total profit TP; along the $x$-axis, the $y$-axis and the $z$-axis, respectively.

TABLE 2. Three numerical examples with respect to various parameters.

\begin{tabular}{llll}
\hline \hline Parameters & Example 1 & Example 2 & Example 3 \\
\hline$A$ & $\$ 10$ & $\$ 10$ & $\$ 15$ \\
$h$ & $\$ 0.4 /$ year & $\$ 0.5 /$ year & $\$ 0.9 /$ year \\
$c$ & $\$ 10$ & $\$ 15$ & $\$ 18$ \\
$s$ & $\$ 40$ & $\$ 30$ & $\$ 35$ \\
$l_{1}$ & $\$ 3$ & $\$ 2$ & $\$ 5$ \\
$l_{2}$ & $\$ 3$ & $\$ 3$ & $\$ 6$ \\
$\gamma$ & 0.3 & 0.4 & 0.2 \\
$I_{c}$ & $\$ 3 /$ year & $\$ 2 /$ year & $\$ 2 /$ year \\
$I_{e}$ & $\times$ & $\times$ & $\$ 4 /$ year \\
$\alpha$ & 500 & 400 & 300 \\
$x$ & 4 & 2 & 3 \\
$b$ & 0.6 & 0.8 & 0.3 \\
$\theta$ & 0.5 & 0.6 & 0.9 \\
\hline
\end{tabular}

Step 4. Applying the conditions.

Step 5. $\mathrm{TP}_{i}$ is concave, $i=1,2$.

Step 6. Obtain $T_{0}, \hat{T}_{1}, \beta_{0}, n_{0}$.

Step 7. If $T_{0}, \hat{T}_{1}, \beta_{0}, n_{0}$ is unique.

Step 8. Output $T^{*}, T_{1}^{*}, \beta^{*}, n^{*}$.

Step 9. Calculate $\operatorname{TP}_{i}\left(T, T_{1}, \beta, n\right), i=1,2$.

\section{NumERICAL EXAMPLES}

In this section, we provide three numerical examples to show the efficiency of the proposed model. The value of the known parameters of the examples is shown in Table 2 and the optimal results of the decision variables and objective functions are shown in Table 3.

By using the software Mathematica, we derive the optimal solutions as follows:

The above solution shows that the optimal profit is $\$ 4865.44$ and optimal cycle time is 0.0166 years. This solution of Example 2 gives less profit than Example 1 as purchasing cost is higher than Example 1 and selling price is lesser than Example 1. The demand of Example 2 is also lower than Example 1. Example 3 shows the 


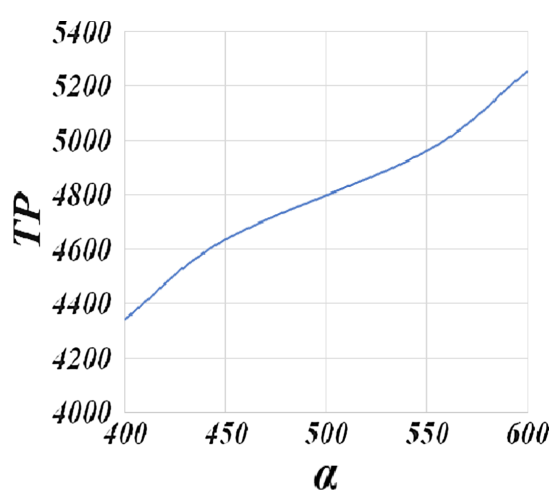

Figure 3. Change of total profit with respect to parameter $\alpha$.

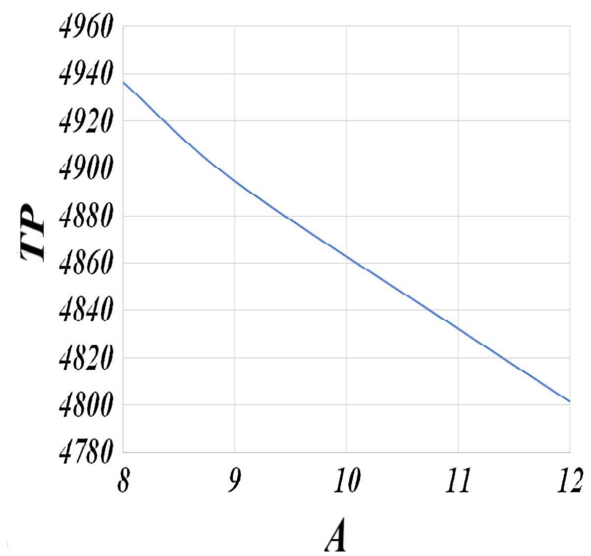

Figure 4. Change of total profit with respect to parameter $A$.

least profit because the cost associated with the parameters is high and demand is low. Not only that, optimal replenishment time is also high so that it can increase the expenditure of the retailer.

Now, the concavity properties of the total profit of Example 2 are shown in Figure 2.

\section{Sensitivity analysis}

We now analyze the effect of changes in system parameters $\alpha, A, \theta, \gamma, l_{2}$ and $l_{1}$ on the optimal values and optimal profits. The sensitivity analysis is performed by changing each parameter by $+20 \%,+10 \%,-10 \%,-20 \%$. The result based on Example 1 are shown in Table 4.

The following observations are drawn on the basis of Table 4:

(i) If the parameter $\alpha$ increases, then the replenishment cycle time $T^{*}$ decreases, the total profit TP increases and the credit period $n^{*}$ also increases. From Table 4 we can see that if the parameter $\alpha$ increases, then the demand also increases, which helps to gain more profit. Figure 3 shows the effect of $\alpha$ on the total profit. Figure 4 shows the effect of $A$ on the total profit.

(ii) If the parameter $\theta$, more precisely deterioration rate, decreases, then replenishment time $T^{*}$ decreases, $\beta$ decreases and the total profit TP increases. From Table 4 we observe that parameter $\theta$ increases, more precisely: when the deterioration rate increases, then total profit decreases. Figure 5 shows the effect of $\theta$ on total profit. 


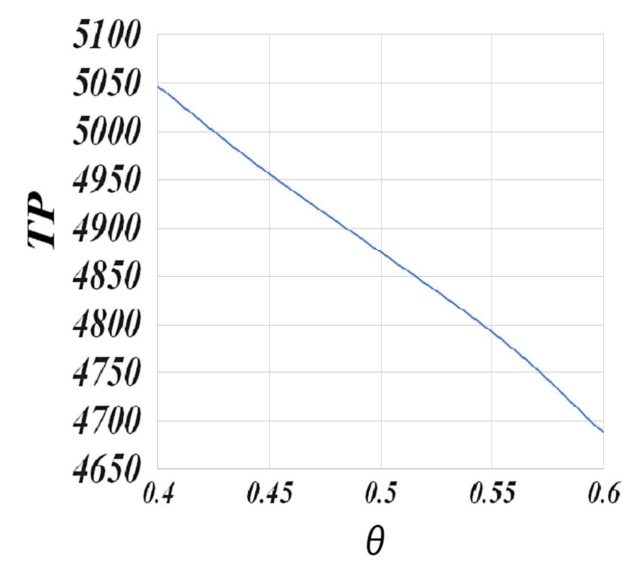

FiguRE 5. Change of total profit with respect to parameter $\theta$.

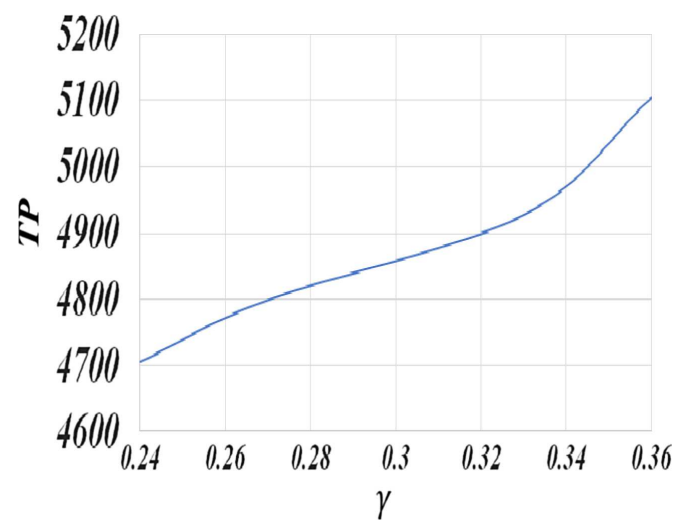

FiguRE 6. Change of total profit with respect to parameter $\gamma$.

(iii) If the parameter $\gamma$, more precisely: the backlogging rate increases, then replenishment time $T^{*}$ decreases and the total profit TP increases. From Table 4 we can see that if $\gamma$ increases, i.e., partial backlogging rises, this helps to increase the selling of the backlogged product and it increases the profit. Figure 6 shows the effect of $\gamma$ on total profit.

(iv) If the parameter $l_{1}$, more precisely: shortage cost increases then replenishment time $T^{*}, \beta$ increases and the total profit TP decreases. From Table 4 we observe that if the shortage cost increases, then total profit decreases. Figure 7 shows the effect of $l_{1}$ on total profit.

(v) If the parameter $l_{2}$, literally lost-sale cost increases then replenishment time $T^{*}$ increases, $\beta$ increases and total profit TP decreases. From Table 4 we can see that the lost-sale cost increases, literally the selling of product decreases, then total profit also decreases. Figure 8 shows the effect of $l_{2}$ on total profit.

\subsection{Stability analysis}

Since the inventory levels do not depend on the delivery times in view of customers' perspective, the stability analysis of the inventory levels is simpler than that of the real inventory. The stability of linear systems is much easier to investigate compared to nonlinear systems. There are only two patterns of dynamic behaviours which are physically possible from a stability perspective. The system could be asymptotically stable, which means 
A. PAUL ET AL.

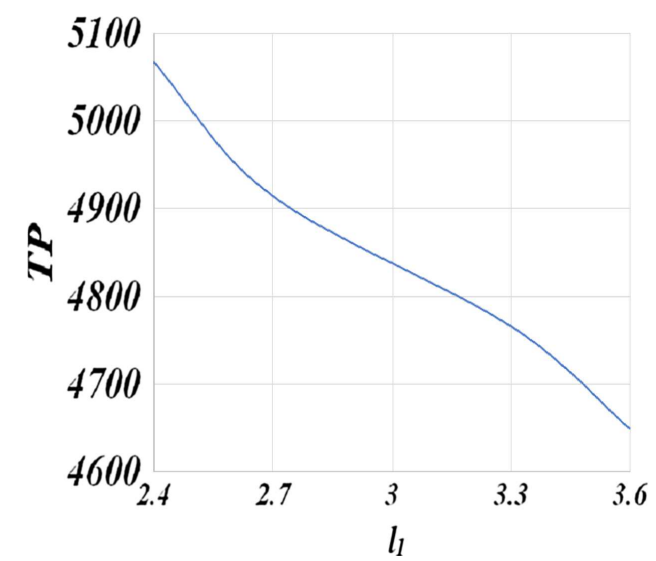

FigURE 7 . Change of total profit with respect to parameter $l_{1}$.

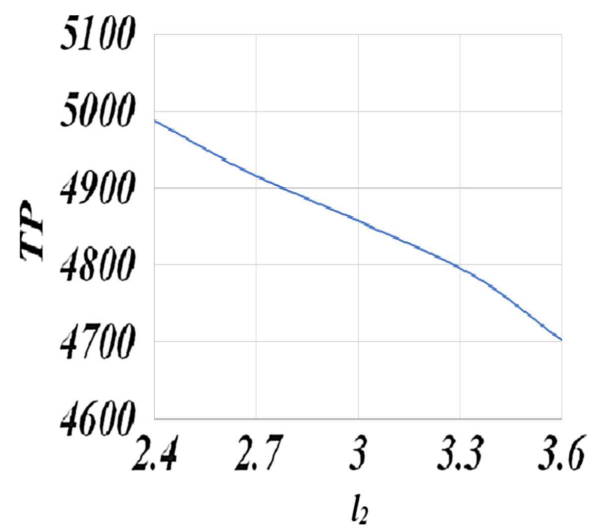

FIgURE 8 . Change of total profit with respect to parameter $l_{2}$.

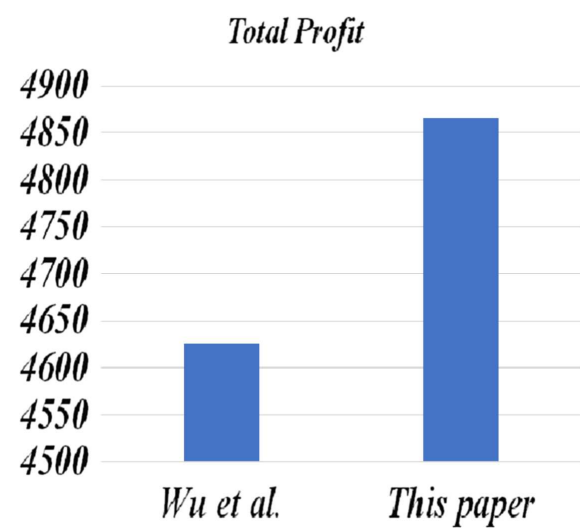

Figure 9. Comparison of total profit. 


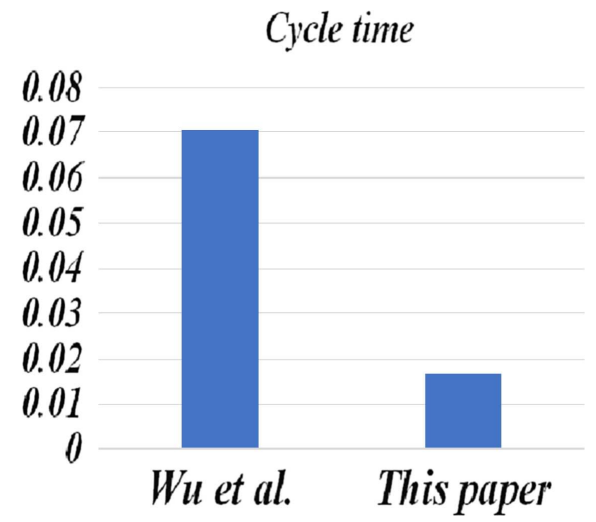

Figure 10. Comparison of total cycle time.

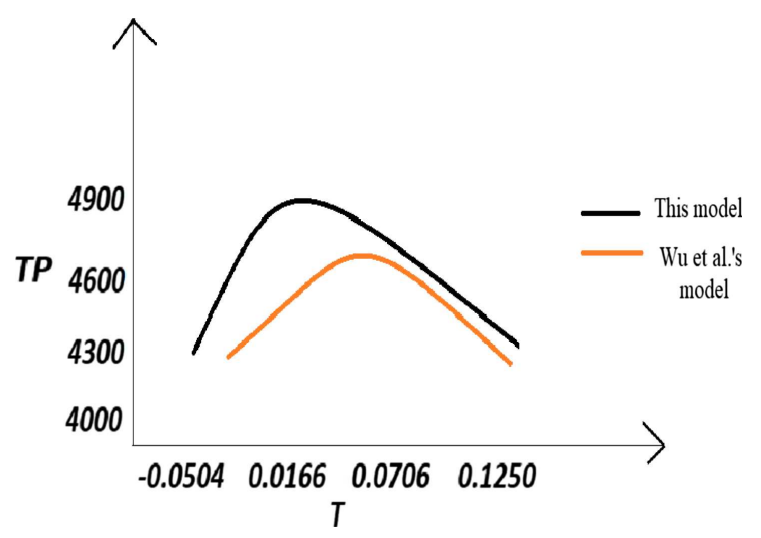

Figure 11. Comparison of Wu et al.'s model and this model.

TABLE 3. Solutions of the numerical examples with respect to various parameters.

\begin{tabular}{llll}
\hline \hline Objectives & Example 1 & Example 2 & Example 3 \\
\hline$\beta$ & 0.26418 & 0.25321 & 0.456817 \\
$n$ & 0.1075 years & 0.110023 years & 0.900232 years \\
$T_{1}$ & 0.00871 years & 0.044861 years & 0.415674 years \\
$T$ & 0.0166 years & 0.0891 years & 1.83782 years \\
$\mathrm{TP}_{1}$ & $\times$ & $\times$ & $\$ 3987.85$ \\
$\mathrm{TP}_{2}$ & $\$ 4865.44$ & $\$ 4448.67$ & $\times$ \\
\hline
\end{tabular}

the trajectory will eventually return to an equilibrium point (node), no matter where it is started (insensitivity to initial value). It could also be unstable, which means the trajectory will escape to infinity.

We could add to our Sensitivity Analysis, which bases here, e.g., on parametric variations along the "ceteris paribus" clause from economics [1], includes the independent variables, and observes the corresponding responses of a dependent variable, a Sensitivity Analysis on the eigenvalues or singular values of the Jacobian matrix of the (system of) differential equations, e.g., at a stationary point. These eigenvalues will depend on the parameters of the system of differential equations. The signs and magnitudes of the eigenvalues will inform us about the 
TABLE 4. Sensitivity analysis for various inventory parameters of Example 1.

\begin{tabular}{|c|c|c|c|c|c|c|c|}
\hline Parameter & value & $T^{*}$ & $T_{1}^{*}$ & $n^{*}$ & $\beta^{*}$ & $\mathrm{TP}$ & $\begin{array}{l}\text { Wu et al.'s } \\
\text { profit }\end{array}$ \\
\hline \multirow{4}{*}{$\alpha$} & 400 & 0.0168203 & 0.00892359 & 0.0769476 & 0.221968 & 4344.2 & 2106.8 \\
\hline & 450 & 0.0167046 & 0.0088053 & 0.0908225 & 0.234356 & 4637.5 & 2180.5 \\
\hline & 550 & 0.0165382 & 0.00863489 & 0.127621 & 0.274228 & 4962.8 & 2340.6 \\
\hline & 600 & 0.016477 & 0.00857165 & 0.151829 & 0.283251 & 5256.6 & 2409.2 \\
\hline \multirow{4}{*}{$A$} & 8 & 0.0155 & 0.00752 & 0.90211 & 0.25925 & 4936.2 & 4780.2 \\
\hline & 9 & 0.0159 & 0.00812 & 0.97554 & 0.26234 & 4894.6 & 4768.4 \\
\hline & 11 & 0.0170 & 0.00923 & 0.11546 & 0.26619 & 4832.4 & 4744.5 \\
\hline & 12 & 0.0174 & 0.00981 & 0.12012 & 0.26932 & 4801.7 & 4720.1 \\
\hline \multirow{4}{*}{$\theta$} & 0.4 & 0.0165506 & 0.00866066 & 0.102195 & 0.211298 & 5046.3 & \multirow{4}{*}{$\begin{array}{l}\text { Parameter } \\
\text { considered in } \\
\text { a different } \\
\text { way }\end{array}$} \\
\hline & 0.45 & 0.0165815 & 0.00868583 & 0.104821 & 0.247845 & 4955.7 & \\
\hline & 0.55 & 0.0166443 & 0.00873718 & 0.110311 & 0.275618 & 4792.4 & \\
\hline & 0.6 & 0.0166761 & 0.00876338 & 0.113181 & 0.281321 & 4688.2 & \\
\hline \multirow{4}{*}{$\gamma$} & 0.24 & 0.0167791 & 0.00881236 & 0.127166 & 0.251552 & 4705.3 & \multirow{4}{*}{$\begin{array}{l}\text { Parameter } \\
\text { is not } \\
\text { considered }\end{array}$} \\
\hline & 0.27 & 0.0166971 & 0.00876255 & 0.116994 & 0.259632 & 4798.6 & \\
\hline & 0.33 & 0.0165258 & 0.00865863 & 0.0987206 & 0.269431 & 4926.4 & \\
\hline & 0.36 & 0.164363 & 0.00860438 & 0.0905415 & 0.274572 & 5102.9 & \\
\hline \multirow{4}{*}{$l_{1}$} & 2.40 & 0.0165604 & 0.00867958 & 0.102112 & 0.239176 & 5066.7 & \multirow{4}{*}{$\begin{array}{l}\text { Parameter } \\
\text { is not } \\
\text { considered }\end{array}$} \\
\hline & 2.70 & 0.0165867 & 0.00869552 & 0.104789 & 0.252156 & 4914.4 & \\
\hline & 3.3 & 0.0166386 & 0.00872701 & 0.110323 & 0.272421 & 4766.2 & \\
\hline & 3.6 & 0.0166642 & 0.00874255 & 0.113182 & 0.281624 & 4649.8 & \\
\hline \multirow{4}{*}{$l_{2}$} & 2.40 & 0.0165762 & 0.00868916 & 0.103711 & 0.248567 & 4987.5 & \multirow{4}{*}{$\begin{array}{l}\text { Parameter } \\
\text { is not } \\
\text { considered }\end{array}$} \\
\hline & 2.70 & 0.0165945 & 0.00870028 & 0.105603 & 0.257689 & 4916.2 & \\
\hline & 3.3 & 0.0166308 & 0.00872232 & 0.109477 & 0.275421 & 4796.6 & \\
\hline & 3.6 & 0.0166488 & 0.00873324 & 0.111459 & 0.282436 & 4703.2 & \\
\hline
\end{tabular}

stability or instability of the system. Herewith, the "Inventory Sensitivity Analysis" will become an "Inventory Stability Analysis".

\subsection{Managerial insights}

The main findings of the paper are outlined in this section. Based on results obtained from Table 4, the following managerial insights have been drawn:

(i) This paper shows a better profit structure than Wu et al.'s model [38]. In Wu et al.'s paper the optimal profit is $\$ 4625.52$, but this paper shows the optimal profit is $\$ 4865.44$ while allowing shortages.

(ii) The optimal replenishment time is also smaller than the Wu et al.'s paper [38] while allowing shortages.

(iii) Selling the product with lower deterioration rate would increase the profit. The more cycle length with deteriorating item leads to less profit.

(iv) If backlogging rate rises, the retailer can earn more profit in less cycle time.

(v) When the shortage period is low, then total profit earned by a retailer will be higher.

\section{Conclusion And FUture WORK}

In this paper, we have determined retailer's optimal replenishment time, credit period and the beginning of shortage period while maximizing the profit. We have considered demand as credit period and price-dependent, where credit-period and price-sensitive parameter are decision variables. It has been shown that replenishment time and optimal credit period exist and are unique in the formulated model. We have calculated the maximum 
profit by considering deterioration in the proposed model. We have used shortages and partial backlogging to give more realistic sense. Some useful theorems have been provided to get the optimal solution. We have used Mathematica to obtain global maximum solution. Sensitivity analysis has been conducted to provide some managerial insights. The managerial insight has been provided in a new direction that helps retailers to gain a highest possible profit. Credit period and default risk have been taken into consideration in this paper, which has a great importance in inventory control. This proposed model shows a better profit function and a better cycle time than Wu et al.'s model (without shortage) (see Figs. 9-11). It is shown that the downstream credit period is more profitable than the both downstream and upstream credit period applicable in a model. Occurrence of shortage in a business system is natural. Thus, this model gives us a more realistic sense. Time plays a vital role in product deterioration. Chance of payment during credit period is also taken into consideration. Our proposed model is applicable for almost all kinds of products with retailer's profit maximization.

For future research, one can extend the mathematical model in several ways. For example, one may choose stochastic demand, quantity discount, etc. One can turn the full trade-credit policy into a partial trade-credit policy, and deterioration may follow the Weibull rule. Researchers may use a complete backlogging policy, and inflation can also be included. In addition to the above, one can extend the model by using probabilistic demand and probabilistic deterioration rate.

Acknowledgements. The author Asim Paul would like to thank to the Council of Scientific \& Industrial Research (CSIR) for the financial support to continue this research work under JRF scheme with sanction no-09/599(0080)/2018-EMR-I. The authors are thankful to the Editor-in-Chiefs and anonymous reviewers for their precious comments that helped too much for improving the manuscript.

\section{Conflict of interest}

The authors of this manuscript would like to announce that there are no difference opinion for publishing the paper.

\section{REFERENCES}

[1] H. Amann, Ordinary Differential Equations: An Introduction to Nonlinear Analysis. Vol. 13 of de Gruyter Studies in Mathematics. Walter de Gruyter \& Co., Berlin, [1990] Birkhäuser, (2010).

[2] S. Bardhan, H. Pal and B.C. Giri, Optimal replenishment policy and preservation technology investment for a non-instantaneous deteriorating item with stock-dependent demand, Oper. Res. Int. J. 19 (2017) 347-368.

[3] H. Barman, M. Pervin, S.K. Roy and G.W. Weber, Back-ordered inventory model with inflation in cloudy-fuzzy environment. J. Ind. Manage. Optim. (2020) DOI: 10.3934/jimo.2020052.

[4] A. Cambini and L. Martein, Generalized Convexity and Optimization: Theory and Application. Springer-Verlag, BerlinHeidelberg (2008).

[5] R.R. Chowdhury, S.K. Ghosh and K.S. Chaudhuri, An order level inventory model for a deteriorating item with time-quadratic demand and time-dependent partial backlogging with shortages in all cycles. Am. J. Math. Manage. Sci. 33 (2014) $75-97$.

[6] C.H. Ho, The optimal integrated inventory policy with price-and-credit-linked demand under two-level trade credit. Comput. Ind. Eng. 60 (2011) 117-126.

[7] Y. Karimian, A. Mirzazadeh, S.H. Pasandideh and M. Namakshen, A geometric programming approach for a vendor managed inventory of a multiretailer multi-item EPQ model. RAIRO:OR 54 (2020) 1401-1418.

[8] M. Lashgari, A.A. Taleizadeh and S.S. Sana, An inventory control problem for deteriorating items with back-ordering and financial considerations under two levels of trade credit linked to order quantity. J. Ind. Manage. Optim. 12 (2016) 1091-1119.

[9] R. Lotfi, G.W. Weber, S.M. Sajadifar and N. Mardani, Interdependent demand in the two-period newsvendor problem. J. Ind. Manage. Optim. 13 (2018) 1.

[10] K.R. Lou and W.C. Wang, Optimal trade credit and order quantity when trade credit impacts on both demand rate and default risk. J. Oper. Res. Soc. 11 (2012) 1-6.

[11] G.C. Mahata and S.K. De, Retailer's optimal credit period and cycle time in a supply chain for deteriorating items with stock and credit-sensitive demand incorporating default risk. Int. J. Appl. Math. Mach. Learn. 5 (2016) 99-113.

[12] A.K. Manna, B. Das and S. Tiwari, Impact of carbon emission on imperfect production inventory system with advance payment base free transportation. RAIRO:OR $\mathbf{5 4}$ (2020) 1103-1117.

[13] Y.Z. Mehrjerdi and R. Lotfi, Development of a mathematical model for sustainable closed-loop supply chain with efficiency and resilience systematic framework. Int. J. Suppl. Oper. Manage. 6 (2019) 360-388. 
[14] R. Moghdani, S.S. Sana and H. Shahbandarzadeh, Multi-item fuzzy economic production quantity model with multiple deliveries. Soft Comput. 24 (2020) 10363-10387.

[15] K.S. Navarro, J.A. Chedid, W.F. Florez, H.O. Mateus, L.E. Cárdenas-Barrón and S.S. Sana, A collaborative EPQ inventory model for a three-echelon supply chain with multiple products considering the effect of marketing effort on demand. J. Ind. Manage. Optim. 16 (2020) 1613-1633.

[16] B. Pal, S.S. Sana and K. Chaudhuri, Two-echelon competitive integrated supply chain model with price and credit period dependent demand. Int. J. Syst. Sci. 47 (2016) 995-1007.

[17] M. Pervin, G.C. Mahata and S.K. Roy, An inventory model with declining demand market for deteriorating items under a trade credit policy. Int. J. Manage. Sci. Eng. Manage. 11 (2015) 243-251.

[18] M. Pervin, S.K. Roy and G.W. Weber, A two-echelon inventory model with stock dependent demand and variable holding cost for deteriorating items. Numer. Algebra Control Optim. 7 (2017) 21-50.

[19] M. Pervin, S.K. Roy and G.W. Weber, Analysis of inventory control model with shortage under time dependent demand and time varying holding cost including stochastic deterioration. Ann. Oper. Res. 260 (2018) 437-460.

[20] M. Pervin, S.K. Roy and G.W. Weber, An integrated inventory model with variable holding cost under two levels of trade-credit policy. Numer. Algebra Control Optim. 8 (2018) 169-191.

[21] M. Pervin, S.K. Roy and G.W. Weber, Deteriorating inventory with preservation technology under price and stock sensitive demand. J. Ind. Manage. Optim. 16 (2019) 1585-1612.

[22] M. Pervin, S.K. Roy and G.W. Weber, Multi-item deteriorating two-echelon inventory model with price and stock dependent demand: a trade credit policy. J. Ind. Manage. Optim. 15 (2019) 1345.

[23] M. Pervin, S.K. Roy and G.W. Weber, An integrated vendor-buyer model with quadratic demand under inspection policy and preservation technology. Hacetepee J. Math. Stat. 49 (2020) 1168-1189.

[24] M. Rastogi and S.R. Singh, An inventory system for varying deteriorating pharmaceutical items with price-sensitive demand and variable holding cost under partial backlogging in healthcare industries. Sādhanā 44 (2019) 95.

[25] M. Rastogi, S.R. Singh, P. Kushwah and S. Tayal, Two warehouse inventory policy with price dependent demand and deterioration under partial backlogging. Decis. Sci. Lett. 6 (2017) 11-22.

[26] S.K. Roy, M. Pervin and G.W. Weber, Imperfection with inspection policy and variable demand under trade-credit: a deteriorating inventory model. Numer. Algebra Control Optim. 10 (2020) 45-74.

[27] S.K. Roy, M. Pervin and G.W. Weber, A two-warehouse probabilistic model with price discount on backorders under two levels of trade credit policy. J. Ind. Manage. Optim. 16 (2020) 553-578.

[28] L.A. San-José and J. Sicilia and D. Alcaide-López-de-Pablo, An inventory system with demand dependent on both time and price assuming backlogged shortages. Eur. J. Oper. Res. 270 (2018) 889-897.

[29] N. Saxena, S.R. Singh and S.S. Sana, A green supply chain model of vendor and buyer for remanufacturing. RAIRO:OR $\mathbf{5 1}$ (2017) 1133-1150.

[30] S. Schaible, Fractional programming. Math. Methods Oper. Res. 27 (1983) 39-54.

[31] S. Sharma, S.R. Singh and M. Ram, An EPQ model for deteriorating items with price sensitive demand and shortages. Int. J. Oper. Res. 23 (2015) 245-255.

[32] A.A. Taleizadeh, M. Yadegari and S.S. Sana, Production models of multiple products using a single machine under quality screening and reworking policies. J. Modell. Manage. 14 (2019) 232-259.

[33] A.A. Taleizadeh, M.P.S. Khanbaglo and L.E. Cárdenas-Barrón, Replenishment of imperfect items in an EOQ inventory model with partial backordering. RAIRO:OR 54 (2020) 413-434.

[34] J.T. Teng, J. Min and Q. Pan, Economic order quantity model with trade credit financing for non-decreasing demand. Omega 40 (2012) 328-335.

[35] J.T. Teng, K.R. Lou and L. Wang, Optimal trade credit and lot size policies in economic production quantity models with learning curve production costs. Int. J. Prod. Econ. 155 (2014) 318-323.

[36] J.T. Teng, L.E. Barron, H.J. Chang, J. Wu and Y. Hu, Inventory lot-size policies for deteriorating items with expiration dates and advance payments. Appl. Math. Modell. 40 (2016) 8605-8616.

[37] J. Wu and Y.L. Chan, Lot sizing policies for deteriorating items with expiration dates and partial trade credit to credit-risk customers. Int. J. Prod. Econ. 155 (2014) 292-301.

[38] J. Wu, L.Y. Ouyang, L.E. Barron and S. Goyal, Optimal credit period and lot size for deteriorating items with expiration dates under two level trade credit financing. Eur. J. Oper. Res. 237 (2014) 898-908.

[39] Q. Zhang, M. Dong, J. Luo and A. Segerstedt, Supply chain coordination with trade credit and quantity discount incorporating default risk. Int. J. Prod. Econ. 153 (2014) 352-360. 